This article is licensed under the Creative Commons Attribution-NonCommercial 4.0 International License (CC BY-NC) (http://www.karger.com/Services/OpenAccessLicense). Usage and distribution for commercial purposes requires written permission.

\title{
Synchronous Endometrial and Ovarian Carcinoma: A Case Series
}

\author{
Georgios-Marios Makris Georgia Manousopoulou Marco- \\ Johannes Battista Ioannis Salloum Georgios Chrelias \\ Charalampos Chrelias
}

Department of Obstetrics and Gynecology, Athens Euroclinic Hospital, Athens, Greece

\section{Keywords}

Endometrial cancer · Ovarian cancer · Synchronous cancer · Surgical staging · Survival ·

Carcinoma - Endometrial carcinoma - Epithelial ovarian cancer - Gynecological cancer .

Neoplasm $\cdot$ Ovarian carcinoma $\cdot$ Prognosis

\section{Abstract}

Synchronous ovarian and endometrial cancer (SEOC) is a rare instance but it accounts for 50$70 \%$ of all synchronous female genital tract tumors. We report three cases of women who were diagnosed with SEOC and underwent surgical staging. All cases were of the endometrioid subtype, grade 1 , both in the ovarian and endometrial component. Two of them were stage Ia/Ia, and the third was stage Ib/Ib. More than 2 years after the diagnosis, all patients were alive and recurrence-free. The present report critically discusses the main characteristics, risk factors, and management of patients with SEOCs. 


\section{Case Reports in Oncology}

Case Rep Oncol 2017;10:732-736

DOI: $10.1159 / 00047950$

(c)

(C) 2017 The Author(s). Published by S. Karger AG, Basel www.karger.com/cro

Makris et al.: Synchronous Endometrial and Ovarian Carcinoma: A Case Series

\section{Introduction}

Synchronous endometrial and ovarian carcinoma (SEOC) is a rare instance but it accounts for $50-70 \%$ of all synchronous female genital tract tumors [1]. Due to the different management and the favorable prognosis of SEOCs, it is important to separate SEOCs from a metastatic disease. In the past, pathologic criteria by Ulbright and Roth [2] were used in order to distinguish synchronous primary tumors from metastasis. SEOCs are characterized by histological dissimilarity of the tumors, no or only superficial myometrial invasion of endometrial cancer, no vascular space invasion of endometrial and ovarian tumor, absence of other evidence of spread, ovarian unilateral tumor, ovarian tumor in the parenchyma and without involvement of the surface of the ovary, dissimilarity of molecular genetic or karyotypic abnormalities in the tumors, and different ploidy of DNA of the tumors [3]. This report describes three cases of SEOCs and critically discusses the main features of these patients.

\section{Case Presentation}

\section{Case 1}

A 46-year-old, para 2, premenopausal woman presented with recent menstrual disorders and abnormal uterine bleeding to the Gynecological Oncology Unit, 3rd Department of Obstetrics and Gynecology, "Attikon" University Hospital, National University of Athens, Greece. She had a history of epileptic seizures and she had been receiving oxcarbazepine. Her family history included a prostate cancer in her father. The clinical examination of the abdomen revealed an undetermined mass which was extended till the umbilicus.

Abdominal ultrasound and magnetic resonance imaging (MRI) showed a mass in the right ovary measuring $117 \times 76 \times 134 \mathrm{~mm}$, a mass in the left ovary measuring $86 \times 94 \times 84$ $\mathrm{mm}$ and absence of ascites. An increase in endometrial thickness was also identified ( $9 \mathrm{~mm}$ ). Serum CA-125 concentration was $274.5 \mathrm{U} / \mathrm{mL}$ (normal range $<35 \mathrm{U} / \mathrm{mL}$ ). After the positive frozen section pathological examination in the ovaries, the patient underwent a total abdominal hysterectomy, bilateral salpingo-oophorectomy, bilateral pelvic and para-aortic lymphadenectomy, omentectomy, appendectomy, and peritoneal biopsies.

Pathological findings revealed an invasive endometrioid carcinoma with squamous differentiation of both ovaries without involvement of the surface of the ovaries (stage Ib, grade 1) and a well-differentiated endometrioid carcinoma of the endometrium with myometrial invasion (stage Ib, grade 1). Peritoneal cytological washing and biopsies, as well as lymph nodes were negative for malignant cells. Radiotherapy (brachytherapy) was planned and the patient received adjuvant chemotherapy with carboplatin and paclitaxel. Up to the last follow-up visit (November 2016), the patient was alive and recurrence-free.

Case 2

A 54-year-old, para 1, obese, postmenopausal (menopause at 51 years) woman was referred to the Gynecological Oncology Unit, 3rd Department of Obstetrics and Gynecology, "Attikon" University Hospital, National University of Athens, Greece. Her presenting complaint was lower abdominal pain during the last month. Her medical history involved a laparoscopic removal of an ovarian cyst in 1988. Examination using ultrasonography showed a 


\section{Case Reports in Oncology}

Case Rep Oncol 2017;10:732-736

DOI: $10.1159 / 000479501$

(c)

(C) 2017 The Author(s). Published by S. Karger AG, Basel www.karger.com/cro

Makris et al.: Synchronous Endometrial and Ovarian Carcinoma: A Case Series

mass of lower abdomen measuring $13 \times 10 \mathrm{~cm}$. MRI identified a cystic lesion with solid components of the left ovary, heterogeneity of myometrium and fluid in Douglas space. CA-125 concentration was $91.3 \mathrm{U} / \mathrm{mL}$ (normal range $<35 \mathrm{U} / \mathrm{mL}$ ).

The patient underwent a total abdominal hysterectomy, bilateral salpingo-oophorectomy, bilateral pelvic and para-aortic lymphadenectomy, omentectomy, appendectomy, and peritoneal biopsies. The fluid in Douglas space and the peritoneal biopsies were negative for malignancy. Pathological findings revealed a well-differentiated endometrioid tumor of the left ovary without invasion of the surface of the ovary (stage Ia, grade 1) and a well-differentiated endometrioid carcinoma of the uterus with invasion of the upper third of myometrium (stage Ia, grade 1). The patient did not receive adjuvant chemotherapy or radiotherapy and we suggested a regular follow-up. Up to the last follow-up visit (November 2016), the patient was alive and recurrence-free.

Case 3

A 78-year-old, para 2, postmenopausal woman with lower abdominal pain and flatulence during the last 6 months presented to the Gynecological Oncology Unit, 3rd Department of Obstetrics and Gynecology, "Attikon" University Hospital, National University of Athens, Greece. Her medical history involved hypothyroidism, hypertension, and osteoporosis. CA-125 concentration was $85 \mathrm{U} / \mathrm{mL}$ (normal range $<35 \mathrm{U} / \mathrm{mL}$ ). MRI and ultrasound examination showed a mass in the right ovary $(10 \mathrm{~cm})$ and endometrial thickening.

The patient underwent a total abdominal hysterectomy, bilateral salpingo-oophorectomy, bilateral pelvic and para-aortic lymphadenectomy, and omentectomy. Pathological findings revealed an endometrioid carcinoma in the ovary (grade 1, stage Ia) and an endometrioid carcinoma in the endometrium (grade 1, stage Ia). The patient did not receive adjuvant chemotherapy or radiotherapy and a regular follow-up was suggested. Up to the last follow-up visit (November 2016), the patient was alive and recurrence-free.

Data of the three reported SEOC cases are summarized in Table 1.

\section{Discussion}

According to various studies, $10 \%$ of women with ovarian cancer have SEOC and about $5 \%$ of women with endometrial cancer are diagnosed with SEOC [4-7]. The majority of women with SEOC are 41-54 years old, $40 \%$ of them are nulliparous, $2 / 3$ of them are premenopausal, and $1 / 3$ are obese [8]. The most common symptom of SEOC is abnormal uterine bleeding, but some patients present in gynecological clinics due to pelvic pain or for a palpable pelvic mass [4, 8]. In our report, women with SEOCs were not nulliparous, 2 of them presented with lower abdominal pain and only 1 of them was premenopausal.

Furthermore, the histologic subtype of both primary tumors is endometrioid in 50-70\% of cases with SEOCs [1] and the primary independent tumors are often grade 1 or 2 [6]. In large studies, the endometrioid type, the low grade and the early stage of SEOCs are associated with a better prognosis and an overall survival of $80-90 \%$ in contrast to the poor prognosis noted in metastatic disease $[6,8]$. On the other hand, a recent international multicenter case-control study showed that patients with SEOC tend to have the same prognosis in comparison with patients with single EC or OC, after matching for age, FIGO stage, histology, year 


\section{Case Reports in Oncology}

Case Rep Oncol 2017;10:732-736

DOI: $10.1159 / 00047950$

(c) 2017 The Author(s). Published by S. Karger AG, Base www.karger.com/cro

Makris et al.: Synchronous Endometrial and Ovarian Carcinoma: A Case Series

of diagnosis and Eastern Cooperative Oncology Group performance status [9]. All patients in our report were diagnosed with low-grade endometrioid carcinomas of the ovary and uterus and were still alive more than 2 years after surgery.

Pretreatment concentration of CA-125 and the tumor stage of the ovary are independent factors in SEOCs [10]. Regarding the pathogenesis of SEOC, the hypothesis of "microenvironment restriction" reflects the low potential of metastasis of SEOC [11]. It is also believed that embryologically similar tissues such as those of the female genital tract are affected from hormonal stimulation and other carcinogenic factors [12]. Additionally by analyzing mitochondrial DNA and by sequencing different genes, a clonality of SEOCs was confirmed $[13,14]$. Nuclear localization of $\beta$-catenin and presence of CTNNB1 mutations are associated with SEOC [15].

Other studies analyze the DNA mismatch repair protein (MMR) expression in SEOC in comparison with the expression of these proteins in Lynch syndrome (hereditary nonpolyposis colorectal cancer, HNPCC). It is already known, that patients with HNPCC also develop endometrial or ovarian cancer [16]. The results of these studies suggest that patients with endometrioid or clear cell ovarian cancer under the age of 53 are at higher risk for loss of MMR (MLH1, MSH2, MSH6) expression and Lynch syndrome [17]; however, the majority of SEOCs are sporadic cancers [18]. In our report, none of the patients had a medical history of HNPCC or other hereditary cancers.

In conclusion, although SEOC is a rare phenomenon, it is necessary to separate this kind of malignancy from a metastatic disease. Molecular biomarkers are anticipated in order to identify the characteristics and underlying pathogenesis of SEOCs.

\section{Statement of Ethics}

The authors have no ethical conflicts to disclose.

\section{Disclosure Statement}

The authors have no conflicts of interest to declare.

\section{References}

1 Singh N: Synchronous tumours of the female genital tract. Histopathology 2010;56:277-285. Ulbright TM, Roth LM: Metastatic and independent cancers of the endometrium and ovary: a clinicopathologic study of 34 cases. Hum Pathol 1985;16:28-34.

3 Scully R, Young R, Clement P: Tumors of the Ovary, Maldeveloped Gonads, Fallopian Tube and Broad Ligament: Atlas of Tumor Pathology. Bethesda, Armed Forces Institute of Pathology, 1998.

$\checkmark 4$ Ayhan A, Yalcin OT, Tuncer ZS, et al: Synchronous primary malignancies of the female genital tract. Eur J Obstet Gynecol Reprod Biol 1992;45:63-66.

-5 Castro IM, Connell PP, Waggoner S, et al: Synchronous ovarian and endometrial malignancies. Am J Clin Oncol 2000;23:521-525. 
6 Zaino R, Whitney C, Brady MF, et al: Simultaneously detected endometrial and ovarian carcinomas - a prospective clinicopathologic study of 74 cases: a gynecologic oncology group study. Gynecol Oncol 2001;83:355-362.

7 AlHilli MM, Dowdy SC, Weaver AL, et al: Incidence and factors associated with synchronous ovarian and endometrial cancer: a population-based case-control study. Gynecol Oncol 2012;125:109-113.

-8 Soliman PT, Slomovitz BM, Broaddus RR, et al: Synchronous primary cancers of the endometrium and ovary: a single institution review of 84 cases. Gynecol Oncol 2004;94:456-462.

-9 Heitz F, Amant F, Fotopoulou C, et al: Synchronous ovarian and endometrial cancer - an international multicenter case-control study. Int J Gynecol Cancer 2014;24:54-60.

10 Song T, Seong SJ, Bae DS, et al: Prognostic factors in women with synchronous endometrial and ovarian cancers. Int J Gynecol Cancer 2014;24:520-527.

11 Anglesio MS, Wang YK, Maassen M, et al: Synchronous endometrial and ovarian carcinomas: evidence of clonality. J Natl Cancer Inst 2016;108:djv428.

12 Eisner RF, Nieberg RK, Berek JS: Synchronous primary neoplasms of the female reproductive tract. Gynecol Oncol 1989;33:335-339.

-13 Guerra F, Girolimetti G, Perrone AM, et al: Mitochondrial DNA genotyping efficiently reveals clonality of synchronous endometrial and ovarian cancers. Mod Pathol 2014;27:1412-1420.

14 Schultheis AM, Ng CK, De Filippo MR, et al: Massively parallel sequencing-based clonality analysis of synchronous endometrioid endometrial and ovarian carcinomas. J Natl Cancer Inst 2016;108:djv427.

15 Irving JA, Catasus L, Gallardo A, et al: Synchronous endometrioid carcinomas of the uterine corpus and ovary: alterations in the beta-catenin (CTNNB1) pathway are associated with independent primary tumors and favorable prognosis. Hum Pathol 2005;36:605-619.

16 Drake AC, Campbell H, Porteous ME, Dunlop MG: The contribution of DNA mismatch repair gene defects to the burden of gynecological cancer. Int J Gynecol Cancer 2003;13:262-277.

17 Vierkoetter KR, Ayabe AR, VanDrunen M, et al: Lynch syndrome in patients with clear cell and endometrioid cancers of the ovary. Gynecol Oncol 2014;135:81-84.

18 Kobayashi Y, Nakamura K, Nomura H, et al: Clinicopathologic analysis with immunohistochemistry for DNA mismatch repair protein expression in synchronous primary endometrial and ovarian cancers. Int J Gynecol Cancer 2015;25:440-446.

Table 1. Characteristics of the three synchronous ovarian and endometrial cancers

\begin{tabular}{llllllllll}
\hline $\begin{array}{l}\text { Age, } \\
\text { years }\end{array}$ & $\begin{array}{l}\text { Date of } \\
\text { surgery }\end{array}$ & $\begin{array}{l}\text { Histological sub- } \\
\text { type of EC }\end{array}$ & $\begin{array}{l}\text { Histological sub- } \\
\text { type of OC }\end{array}$ & $\begin{array}{l}\text { Grade of Grade } \\
\text { EC OC }\end{array}$ & $\begin{array}{l}\text { Stage } \\
\text { of EC }\end{array}$ & $\begin{array}{l}\text { Stage } \\
\text { of OC }\end{array}$ & $\begin{array}{l}\text { Survival, } \\
\text { months }\end{array}$ & $\begin{array}{l}\text { Recurrence- } \\
\text { free survival, } \\
\text { months }\end{array}$ \\
\hline 46 & May 2014 & Endometrioid & Endometrioid & 1 & 1 & Ib & Ib & $31+$ & $31+$ \\
54 & March 2014 & Endometrioid & Endometrioid & 1 & 1 & Ia & Ia & $33+$ & $33+$ \\
78 & July 2014 & Endometrioid & Endometrioid & 1 & 1 & Ia & Ia & $29+$ & $29+$ \\
\hline
\end{tabular}

EC, endometrial cancer; OC, ovarian cancer. 